\title{
Leaching, carbonation and chloride ingress in reinforced alkali- activated fly ash mortars
}

\author{
Gregor J. G. Gluth ${ }^{1, *}$, Petr Hlaváček ${ }^{1}$, Steffi Reinemann², Gino Ebell², and Jürgen Mietz ${ }^{2}$ \\ ${ }^{1}$ Bundesanstalt für Materialforschung und -prüfung (BAM), 7.4 Technology of Construction Materials, 12205 Berlin, Germany \\ ${ }^{2}$ Bundesanstalt für Materialforschung und -prüfung (BAM), 7.6 Corrosion and Corrosion Protection, 12205 Berlin, Germany
}

\begin{abstract}
Alkali-activated fly ash mortars were studied with regard to durability-relevant transport coefficients and the electrochemical behaviour of embedded carbon steel bars on exposure of the mortars to leaching, carbonation and chloride penetration environments. The transport coefficients differed considerably between different formulations, being lowest for a mortar with BFS addition, but still acceptable for one of the purely fly ash-based mortars. Leaching over a period of $\sim 300$ days in de-ionized water did not lead to observable corrosion of the embedded steel, as shown by the electrochemical data and visual inspection of the steel. Exposure to $100 \% \mathrm{CO}_{2}$ atmosphere caused steel depassivation within approx. two weeks; in addition, indications of a deterioration of the mortar were observed. The results are discussed in the context of the different reaction products expected in high- and low-Ca alkali-activated binders, and the alterations caused by leaching and carbonation
\end{abstract}

\section{Introduction}

Alkali-activated materials (AAMs) are receiving a lot of attention, because of their potential to either perform better than conventional cements in specific applications or to be produced more cost-effective and/or environmentally friendly. However, there are still issues that need to be understood concerning the durability of structures made from AAMs, particularly regarding carbonation, chloride ingress and associated corrosion of embedded carbon steel reinforcement [1].

Recent research has highlighted the importance of the redox conditions in the pore solution of AAMs for steel corrosion [2], and indicated that AAMs with a moderate to high blast furnace slag (BFS) content generally are able to protect the reinforcement from corrosion over the long-term when subjected to chlorides or carbonation [27]. The published results regarding the behaviour of carbon steel in low-Ca AAMs (i.e. without BFS) are often less positive and appear to partly contradict each other [2,8-15]; on the other hand, there are applications in which the use of (reinforced) low-Ca AAMs can be of advantage, e.g. when high-temperature resistance $[16,17]$ or resistance against chemical attack [18] is required. This justifies further research into the ability of these materials to protect steel reinforcement, including compilation of more data regarding threshold values for depassivation and the onset of steel corrosion. In addition, only limited data regarding relevant transport coefficients is available [19-22], and should be complemented by additional measurements.
In this contribution, we present results from an ongoing project in this field that is aimed at determining the critical chloride content in fly ash-based AAMs under realistic conditions, i.e. including partly carbonated and/or leached materials. In the first part of the study, different transport parameters (chloride migration and diffusion, carbonation, and gas permeability) were determined. The second part included exposure of alkaliactivated mortars and CEM I-based reference mortars with embedded carbon steel reinforcement to leaching, carbonation and chloride environments, and recording of the ohmic and the polarisation resistance as well as the free corrosion potential over periods up to 274 days.

\section{Experimental}

\subsection{Materials}

Mortars for the determination of transport coefficients were produced from two hard coal fly ashes, denoted EFA $\mathrm{S}$ and EFA H, and BFS; their chemical compositions are shown in Table 1. Activator solutions were waterglass with a composition $28.5 \pm 2.0 \mathrm{wt} \% \quad \mathrm{SiO}_{2}$, $15.0 \pm 0.5 \mathrm{wt} \% \mathrm{Na}_{2} \mathrm{O}$, remainder: $\mathrm{H}_{2} \mathrm{O} ; 12 \mathrm{M} \mathrm{NaOH}$ solution; and additional water, if required.

The mix-designs of the alkali-activated mortars are shown in Table 2, together with the resulting overall modulus $\left(M_{\mathrm{s}}\right.$; molar $\mathrm{SiO}_{2} / \mathrm{Na}_{2} \mathrm{O}$ ratio $)$ of the activator solutions. One of the mortars was produced with $50-\%$ substitution of fly ash by BFS to study the influence of an increased $\mathrm{Ca}$ content of the binder on the transport co-

* Corresponding author: gregor.gluth@bam.de 
efficients. The CEM I-based mortar had the composition $1304 \mathrm{~kg} / \mathrm{m}^{3}$ quartz sand $0-4 \mathrm{~mm} ; 606 \mathrm{~kg} / \mathrm{m}^{3}$ CEM I; 273 $\mathrm{kg} / \mathrm{m}^{3}$ water (i.e. $\left.\mathrm{w} / \mathrm{c}=0.45\right)$.

Table 1. Chemical compositions of EFA S, EFA H and BFS.

\begin{tabular}{|l|c|c|c|}
\hline \multicolumn{1}{|c|}{$($ wt $\%)$} & EFA S & EFA H & BFS \\
\hline $\mathrm{SiO}_{2}$ & 48.94 & 57.41 & 35.10 \\
\hline $\mathrm{Al}_{2} \mathrm{O}_{3}$ & 25.08 & 17.48 & 11.03 \\
\hline $\mathrm{Fe}_{2} \mathrm{O}_{3}$ & 5.52 & 7.02 & 0.42 \\
\hline $\mathrm{TiO}_{2}$ & 5.12 & 1.31 & 0.77 \\
\hline $\mathrm{CaO}$ & 3.14 & 7.45 & 40.64 \\
\hline $\mathrm{MgO}$ & 1.30 & 0.60 & 8.26 \\
\hline $\mathrm{Na}_{2} \mathrm{O}$ & 1.09 & 0.53 & 0.55 \\
\hline $\mathrm{K}_{2} \mathrm{O}$ & 3.99 & 0.97 & 0.49 \\
\hline $\mathrm{SO}_{3}$ & 0.74 & 0.80 & 2.20 \\
\hline $\mathrm{LOI}^{2}$ & 4.65 & 4.09 & 1.05 \\
\hline
\end{tabular}

Table 2. Mix-designs of the alkali-activated mortars. All values, except $M_{\mathrm{s}}$, are given in $\mathrm{kg} / \mathrm{m}^{3}$ (mortar).

\begin{tabular}{|l|c|c|c|c|}
\hline & $\begin{array}{c}\text { FA } \\
\text { NaOH }\end{array}$ & $\begin{array}{c}\text { FA } \\
\text { WG }\end{array}$ & $\begin{array}{c}\text { FA- } \\
\text { BFS }\end{array}$ & FA5 \\
\hline EFA S & 612 & 583 & 312 & - \\
\hline EFA H & - & - & - & 580 \\
\hline BFS & - & - & 312 & - \\
\hline Waterglass sln. & - & 96 & - & 214 \\
\hline 12 M NaOH sln. & 275 & 164 & 312 & 98 \\
\hline Water & - & 32 & - & 6 \\
\hline$M_{\text {s }}$ & 0 & 0.50 & 0 & 1.12 \\
\hline $\begin{array}{l}\text { Quartz sand } \\
0-4 \text { mm }\end{array}$ & 1333 & 1333 & 1333 & 1333 \\
\hline
\end{tabular}

Mixing of the mortars was done in a $30-\mathrm{dm}^{3}$ rotating pan mixer for 4 minutes. The mortars were cast either in 100 -mm cube moulds, $\varnothing=100 \mathrm{~mm} \times h=300 \mathrm{~mm}$ cylinder moulds, or $40 \mathrm{~mm} \times 40 \mathrm{~mm} \times 160 \mathrm{~mm}$ prism moulds, depending on the subsequent test method.

Electrochemical measurements were done on corrugated BSt 500 carbon steel rebars with a diameter of 10 $\mathrm{mm}$ and a length of $120 \mathrm{~mm}$, embedded in FA5 mortars or CEM I-mortars. Stainless steel rods were welded to the ends of the rebars, the assemblage cleaned by grit blasting (corundum grit) and then installed in the prism moulds into pre-drilled locating holes (Fig. 1). This setup avoids the use of spacers which can introduce flaws that effect the transport to the steel/mortar interface. After curing (see below), the mortar cover of the rebars was decreased from $10 \mathrm{~mm}$ to $5 \mathrm{~mm}$ by grinding off a layer of $5 \mathrm{~mm}$ thickness from the prisms (at the bottom edge in Fig. 1); subsequently, the prisms were cleaned in an ultrasonic bath in water.

The alkali-activated mortars were cured at $80{ }^{\circ} \mathrm{C}$ and $80 \%$ relative humidity (RH) for $24 \mathrm{~h}$. After this period, they were stripped from the moulds and stored at $23{ }^{\circ} \mathrm{C} / 50 \% \mathrm{RH}$ until required for testing $(6 \mathrm{~d}$ for the determination of the transport coefficients, the carbonation depth and strengths). The CEM I-mortars were cured at $23{ }^{\circ} \mathrm{C}$ in closed containers above water $(\sim 99 \%$ $\mathrm{RH})$ for $28 \mathrm{~d}$, after which time samples for strength testing were taken, and subsequently stored at $23{ }^{\circ} \mathrm{C} /$ $50 \% \mathrm{RH}$.

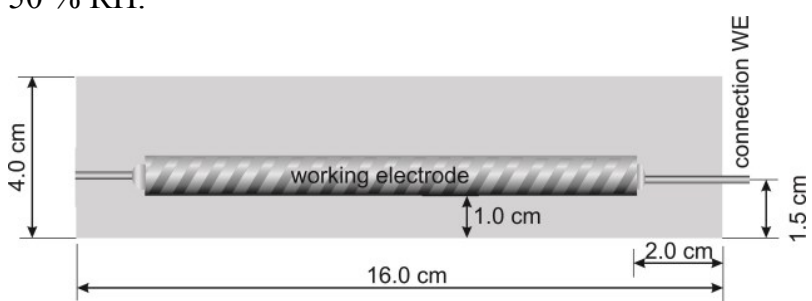

Fig. 1. Schematic of the mortar prisms with embedded rebar.

Compressive and flexural strength testing were done on $40 \mathrm{~mm} \times 40 \mathrm{~mm} \times 160 \mathrm{~mm}$ mortar prism without reinforcement in accordance with the testing conditions (loading rate etc.) prescribed in EN 196-1 for testing of cement. The strengths were determined after curing regimes as described in the above paragraph; the results are shown in Table 3. The compressive strength of mortar FA-BFS was significantly lower than what is usually observed for well-designed alkali-activated BFS/fly ash blends. The reason for this was that no optimization of the activator composition was attempted; instead, mortar FA-BFS served only to demonstrate the influence of the substitution of fly ash for BFS, compared to mortar FA $\mathrm{NaOH}$ (without change of the activator).

Table 3. Compressive and flexural strengths of the mortars. Values are given in $\mathrm{MPa}$; values after the \pm sign denote one standard deviation.

\begin{tabular}{|l|c|c|}
\hline & $\begin{array}{c}\text { Compressive } \\
\text { strength }\end{array}$ & $\begin{array}{c}\text { Flexural } \\
\text { strength }\end{array}$ \\
\hline FA NaOH & $34.7 \pm 1.0$ & $5.2 \pm 0.3$ \\
\hline FA WG & $58.2 \pm 0.9$ & $9.1 \pm 0.3$ \\
\hline FA-BFS & $26.5 \pm 0.7$ & $4.2 \pm 0.2$ \\
\hline FA5 & $80.9 \pm 2.0$ & $7.8 \pm 0.4$ \\
\hline CEM I & $70.6 \pm 1.9$ & $7.1 \pm 0.3$ \\
\hline
\end{tabular}

\subsection{Methods}

Chloride migration coefficients $\left(D_{\text {nssm }}\right)$, chloride diffusion coefficients $\left(D_{\mathrm{e}}\right)$, gas permeability coefficients $(K)$ and carbonation depths $\left(d_{\mathrm{k}}\right)$ were determined in accordance with NT BUILD 492 (1999-11) ['rapid chloride migration (RCM) test'], NT BUILD 443 (1995-11), the recommendation of RILEM TC 116-PCD [23] and DIN EN 13295:2004-08 (i.e. $1 \% \mathrm{CO}_{2}$ ), respectively, except modifications of the curing regime $\left(1 \mathrm{~d}\right.$ at $80{ }^{\circ} \mathrm{C} / 80 \%$ $\mathrm{RH}$; see Section 2.1) and the use of air as the test gas for the permeability measurements. Gas permeability measurements were performed on oven-dried specimens $\left(40{ }^{\circ} \mathrm{C}\right.$ for $7 \mathrm{~d}$ ) and on undried specimens (equilibrated at $\left.20^{\circ} \mathrm{C} / 65 \% \mathrm{RH}\right)$.

Electrochemical measurement on steel rebars were done for rebars embedded in mortar FA5 (as this mortar exhibited the lowest transport coefficients of the alkaliactivated mortars without BFS addition; see Section 3.1), and CEM I-mortar as a reference. 
Ohmic resistance $\left(R_{\mathrm{el}}\right)$ and polarisation resistance $\left(R_{\mathrm{p}}\right)$ were obtained by means of the galvanostatic pulse technique under the following conditions: $\Delta t=20 \mathrm{~s} ; I=$ $\pm(8 \ldots 200) \mu \mathrm{A}$. For these measurements, the specimens were partially immersed, together with the reference electrode $(\mathrm{Ag} / \mathrm{AgCl}($ sat.) ), in tap water in a purpose-built acrylic glass cell equipped with the counter electrode (mixed metal oxide mesh); for a schematic see Ref. [24]. Anodic as well as cathodic pulses were applied, with a period of $\sim 20 \mathrm{~min}$ in between; since there was always good agreement between the results, only those obtained with anodic pulses will be reported below.

Mortar prisms for leaching were first preconditioned at $\sim 21{ }^{\circ} \mathrm{C}$ and $\sim 98 \% \mathrm{RH}$ for $90 \mathrm{~d}$, and then immersed in a container filled with de-ionized water $(\leq 16$ prisms in $\sim 50 \mathrm{dm}^{3}$ water). During the first 132 days of leaching, the water in the container was exchanged approx. weekly with new, de-ionized water; the $\mathrm{pH}$ of the water was measured at irregular intervals for CEM I and FA5. The recorded $\mathrm{pH}$ values decreased for both mortars from $\sim 9 \ldots 11$ in the first month to $\sim 8 \ldots 8.5$ after three months, indicating that leaching was significant already by this time. Subsequently, the water was continuously exchanged via an inlet and an outlet at a flow rate of $\sim 15 \mathrm{dm}^{3} / \mathrm{h}$; the measured $\mathrm{pH}$ values were then $\sim 6 \ldots 7$. Specimens were removed from the container and allowed to dry in air for $\sim 20 \mathrm{~h}$ on a lab bench before the electrochemical measurements.

Accelerated carbonation was conducted in a closed container that was continuously flushed with $100 \% \mathrm{CO}_{2}$ at a flow rate of $\sim 4 \mathrm{dm}^{3} / \mathrm{h}$. After the electrochemical measurements, specimens were allowed to dry in air for $\sim 24 \mathrm{~h}$ before being put pack in the carbonation box. After 53 days, some of the samples were removed from the carbonation box, immersed in tap water for 5 days, and subsequently partially immersed (rebar at the bottom, but above the liquid surface) in $1 \mathrm{M} \mathrm{NaCl}$ solution.

\section{Results and discussion}

\subsection{Transport coefficients}

Table 4 shows the transport coefficients and carbonation depths of the alkali-activated mortars [25]. Considering that the scatter of transport coefficient measurements is usually relatively large, the agreement between the chloride migration and diffusion measurements can be regarded as very good. This means that the RCM test according to NT BUILD 492 is sufficient to determine the chloride transport coefficients of alkali-activated fly ash mortars (including one with BFS addition). It is noted

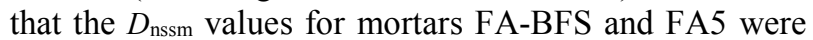
close to $16 \times 10^{-12} \mathrm{~m}^{2} / \mathrm{s}$, which has been reported as the limit for 'acceptable resistance to chloride penetration' for concrete [26].

The relative order of the carbonation depths of the mortars were in line with their chloride transport coefficients, viz. lowest for FA-BFS and FA5.

These results demonstrate that the addition of BFS to AAMs significantly decreases their durability-relevant transport coefficients ( $c f$. Ref. [7]). At the same time, the results show that well-designed low-Ca AAMs (FA5 in this case) too exhibit transport coefficients that are in the range of conventional cement-based materials, and thus do not exclude application as construction materials.

A large discrepancy between these results and the gas permeabilities after oven-drying is apparent from Table 4. While FA-BFS exhibited the lowest chloride transport coefficients and carbonation depth, its gas permeability was at least one order of magnitude higher than those of the other mortars. The results of the measurements on undried samples, however, were in accord with the expected order of permeabilities. While the result for the undried mortar FA WG was similar to the results for the oven-dried FA WG, the measured gas permeability of FA-BFS was three magnitudes lower for the undried samples than for the oven-dried samples.

Table 4. Transport coefficients and carbonation depths of the alkali-activated mortars.

\begin{tabular}{|c|r|r|r|c|}
\hline & $\begin{array}{c}\text { FA } \\
\text { NaOH }\end{array}$ & $\begin{array}{c}\text { FA } \\
\text { WG }\end{array}$ & $\begin{array}{c}\text { FA- } \\
\text { BFS }\end{array}$ & FA5 \\
\hline $\begin{array}{c}D_{\mathrm{nssm}} \\
{\left[10^{-12} \mathrm{~m}^{2} / \mathrm{s}\right]}\end{array}$ & 205.4 & 169.2 & 14.0 & 24.4 \\
\hline $\begin{array}{c}D_{\mathrm{e}} \\
{\left[10^{-12} \mathrm{~m}^{2} / \mathrm{s}\right]}\end{array}$ & 98.6 & 121.0 & 7.9 & 41.9 \\
\hline$d_{\mathrm{k}}[\mathrm{mm}]$ & 7.7 & 5.6 & 1.1 & 3.1 \\
\hline $\begin{array}{c}K(\text { oven-dried }) \\
{\left[10^{-17} \mathrm{~m}^{2}\right]}\end{array}$ & 105.0 & 18.9 & 793.0 & 1.7 \\
\hline $\begin{array}{c}K(\text { undried }) \\
{\left[10^{-17} \mathrm{~m}^{2}\right]}\end{array}$ & n.d. & 14.6 & 1.3 & n.d. \\
\hline
\end{tabular}

n.d.: not determined

This behaviour is explained by the different chemical composition of FA-BFS compared to the other mortars. The higher $\mathrm{Ca}$ content of FA-BFS $(\sim 20 \mathrm{wt} \% \mathrm{CaO}$ referred to the dry binder mass) will lead to the formation of $\mathrm{C}-(\mathrm{A}-) \mathrm{S}-\mathrm{H}$ gel as the main binding phase; on the contrary, 'N-A-S-H' gel is the main binding phase of AAMs with a Ca content below $\sim 10 \%$ [27]. The predominance of C-(A-)S-H in high-Ca AAMs is responsible for pore refinement [28] and thus one the reasons for the observed reduction of transport coefficients of FA-BFS, discussed above. However, C-(A-)S-H is very sensitive to heating, i.e. it will tend to collapse on drying [29], leading to a significant coarsening of the pore structure of this mortar during drying, while 'N-A-S-H' gel is not a hydrate and appears to be rather stable under ovendrying conditions. It can thus be concluded that gas permeability measurements after oven-drying can provide a useful indication of the transport properties of low-Ca AAMs, but not of moderate- to high-Ca AAMs.

\subsection{Behaviour of embedded steel}

\subsubsection{Leaching}

Fig. 2 shows the free corrosion potential of steel in FA5and CEM I-mortars under leaching conditions. While $E_{\text {corr }}$ remained approximately constant with some fluctuations (in the range $\sim 10 \ldots 110 \mathrm{mV}$ ) for the CEM I- 
mortar, it increased slowly from $\sim 35 \mathrm{mV}$ to $\sim 200 \mathrm{mV}$ after $274 \mathrm{~d}$ for the FA5-mortar.

As shown in Fig. 3, also the ohmic resistance of the FA5-mortar and the polarisation resistance of the steel in the FA5-mortar increased steadily during leaching, though at all times $R_{\mathrm{el}}$ of FA5 was lower than $R_{\mathrm{el}}$ of CEM I. The reason for the sharp increase of $R_{\mathrm{el}}$ of the CEM I-mortar at the start of leaching, and its decline on changing the leaching conditions from water exchange to continuous water flow is not clear yet. Nevertheless, $R_{\mathrm{p}}$ of the steel in FA5 and in CEM I were always similar (evolving from $\sim 60 \mathrm{k} \Omega \mathrm{cm}^{2}$ to $70 \ldots 100 \mathrm{k} \Omega \mathrm{cm}^{2}$ ), suggesting a similar state of the steel in both mortars; the $E_{\text {corr }}$ and $R_{\mathrm{p}}$ values show that this was a passive state.

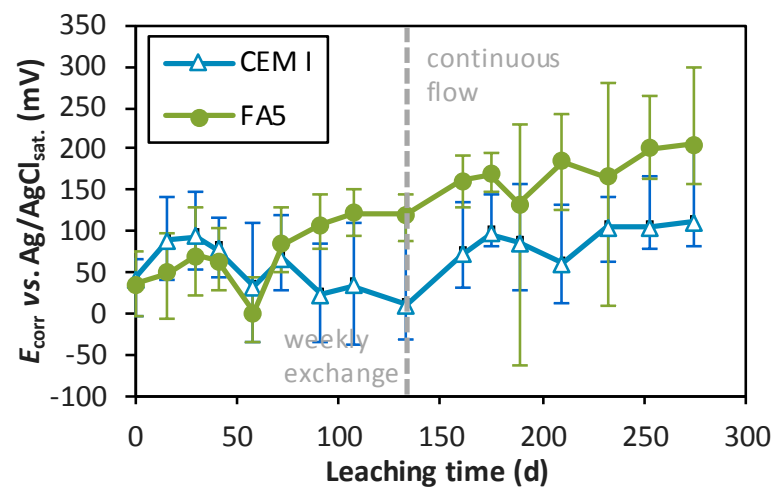

Fig. 2. Free corrosion potential of steel rebars embedded in CEM I-mortar and in FA5-mortar under leaching conditions (de-ionized water; 5-mm mortar cover). Error bars represent $\min / \max$ values.
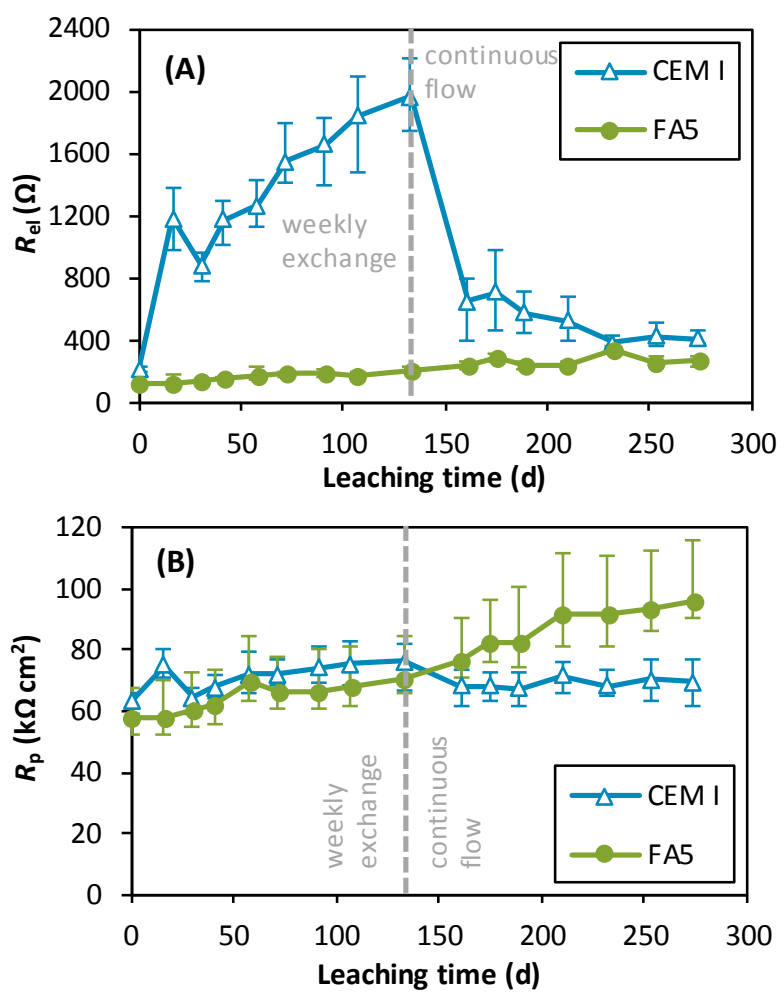

Fig. 3. (A) ohmic resistance and (B) polarisation resistance for steel rebars embedded in CEM I-mortar and in FA5-mortar under leaching conditions (de-ionized water; 5-mm mortar cover). Error bars represent $\mathrm{min} / \max$ values.
These results show that in both mortars leaching did not induce a drop in $\mathrm{pH}$ large enough to cause depassivation. These conclusions were confirmed by visual inspection of the rebars after $316 \mathrm{~d}$ of leaching (Fig. 4): The steel in both mortars showed no signs of corrosion. This means that, despite its relatively large transport coefficients, FA5 was able to protect the embedded steel under very severe leaching conditions over the observation period of $\sim 300 \mathrm{~d}$, implying satisfactory behaviour under real-world conditions too.

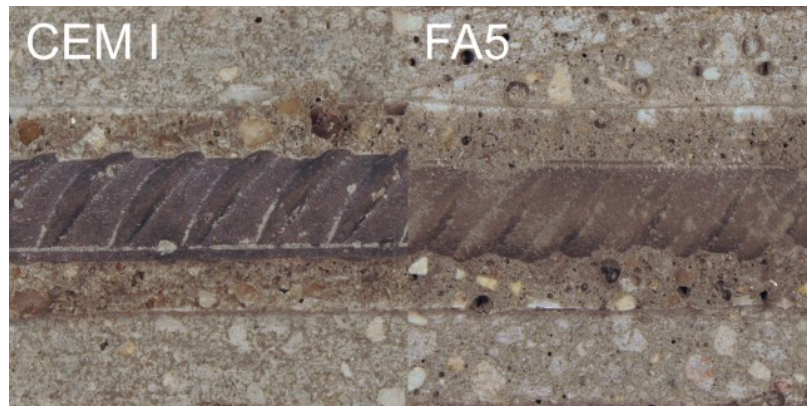

Fig. 4. Steel rebars embedded in CEM I-mortar (left) and FA5mortar (right) after $316 \mathrm{~d}$ under leaching conditions (de-ionized water; 5-mm mortar cover).

$\mathrm{Na}^{+}$diffusion coefficients for hardened alkali-activated fly ash pastes have been reported to be in the range $0.5 \ldots 27.0 \times 10^{-12} \mathrm{~m}^{2} / \mathrm{s}$ by Lloyd et al. [19] and $1.9 \times$ $10^{-12} \mathrm{~m}^{2} / \mathrm{s}$ by Škvára et al. [20]. The $\mathrm{Na}^{+}$diffusion coefficient of the FA5-mortar was determined in the present study by fitting Na profiles after leaching, obtained by laser-induced breakdown spectroscopy (LIBS; details will be presented elsewhere), to be $\sim 0.5 \times 10^{-12} \mathrm{~m}^{2} / \mathrm{s}$. Evidently, this value sufficed to maintain a high $\mathrm{pH}$ at the steel/mortar interface for $\sim 300 \mathrm{~d}$. It is noted that the determined value for $\mathrm{Na}^{+}$diffusion deviates significantly from the value for chloride diffusion (Table 4), which indicates differences in the strength of the interactions of these ions with pore surfaces and/or other solutes.

\subsubsection{Accelerated carbonation and chloride penetration}

Figs. 5 and 6 show $E_{\text {corr, }}$ and $R_{\mathrm{el}}$ and $R_{\mathrm{p}}$, respectively, during exposure to accelerated carbonation conditions $\left(100 \% \mathrm{CO}_{2}\right)$ for $53 \mathrm{~d}$, and subsequent partial immersion of the carbonated specimens in $1 \mathrm{M} \mathrm{NaCl}$ solution. The starting value of $E_{\text {corr }}$ for FA5 (before the onset of carbonation) was significantly lower than the starting value of the specimens for leaching (Fig. 2), but the recorded value (approx. $-200 \mathrm{mV}$ vs. the $\mathrm{Ag} / \mathrm{AgCl}$ (sat.) electrode) still indicates that the steel was in a passive state $[2,4,5,8]$, which is supported by the corresponding $R_{\mathrm{p}}$ of $\sim 60 \mathrm{k} \Omega \mathrm{cm}^{2}$.

Already after $16 \mathrm{~d}$ of accelerated carbonation, $R_{\mathrm{p}}$ for both, the FA5-mortar and the CEM I-mortar, had dropped significantly, indicating carbonation of the mortars and depassivation of the embedded steel. Nevertheless, $E_{\text {corr }}$ of FA5 did not decline significantly, and the $E_{\text {corr }}$ of CEM I had decreased, but remained at values (around 
$-200 \mathrm{mV}$ ) that do not necessarily signal depassivation. Subsequently, $R_{\mathrm{p}}$ for both mortars remained low.

Also, $R_{\mathrm{el}}$ of the FA5-mortar decreased within the first $16 \mathrm{~d}$, possibly indicating a coarsening of the pore structure (cf. Ref. [30]); however, this assumption remains to be tested by microstructural analyses. $R_{\mathrm{el}}$ of the CEM Imortar increased steadily during accelerated carbonation, presumably due to the reduction of its porosity induced by the carbonation (i.e. calcite formation; $c f$. Ref. [31]).

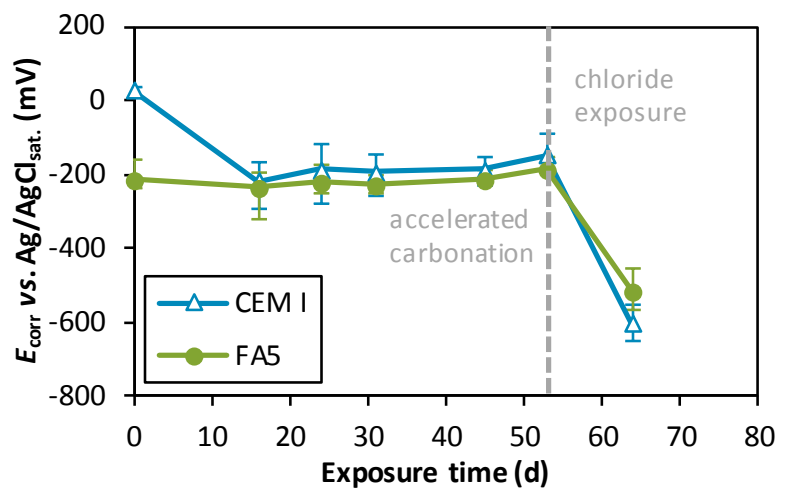

Fig. 5. Free corrosion potential of steel rebars embedded in CEM I-mortar and in FA5-mortar under accelerated carbonation conditions (100\% $\mathrm{CO}_{2} ; 5$-mm mortar cover) and subsequent exposure to $1 \mathrm{M} \mathrm{NaCl}$ solution. Error bars represent $\mathrm{min} / \mathrm{max}$ values.
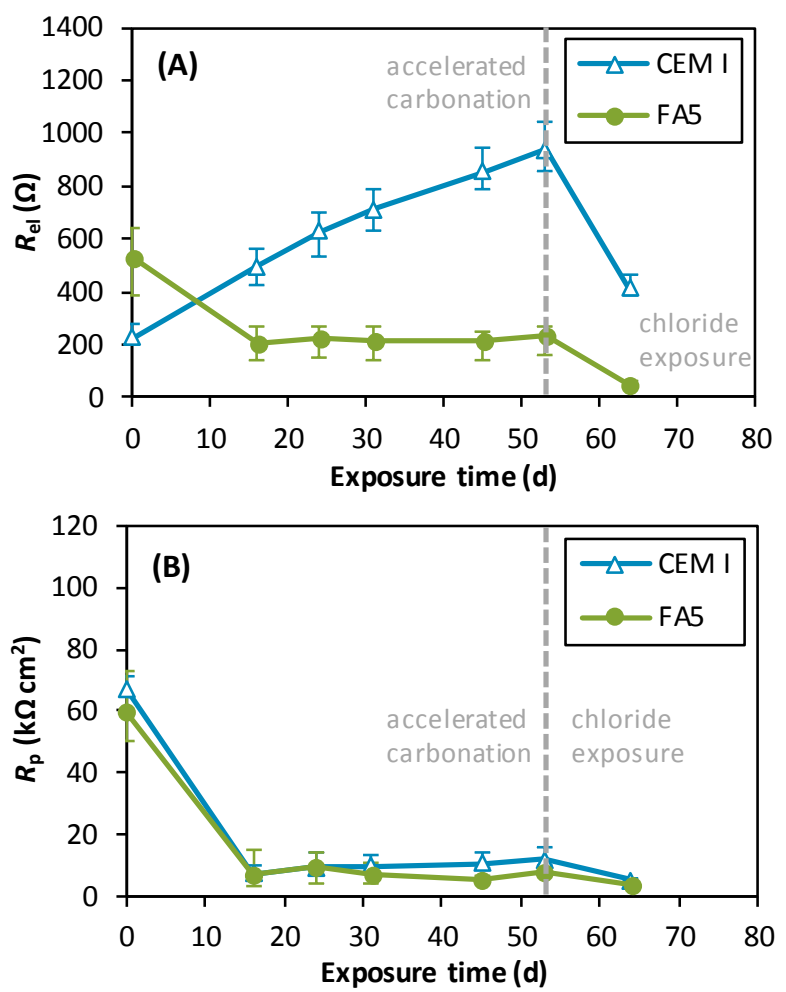

Fig. 6. (A) ohmic resistance and (B) polarisation resistance for steel rebars embedded in CEM I-mortar and in FA5-mortar under accelerated carbonation conditions $\left(100 \% \mathrm{CO}_{2} ; 5-\mathrm{mm}\right.$ mortar cover) and subsequent exposure to $1 \mathrm{M} \mathrm{NaCl}$ solution. Error bars represent $\mathrm{min} / \mathrm{max}$ values.

The steel rebars in both mortars showed signs of severe corrosion after $137 \mathrm{~d}$ of accelerated carbonation
(Fig. 7), confirming the conclusion drawn above from the $R_{\mathrm{p}}$ values regarding depassivation of the steel.

These results demonstrate that exposure to a $100-\%$ $\mathrm{CO}_{2}$ atmosphere presents an extremely severe attack to low-Ca AAMs, leading to depassivation of the steel reinforcement (mortar cover: $5 \mathrm{~mm}$ ) within 16 days, and possibly also deterioration of the binder matrix. This is related, inter alia, to the influence of the $\mathrm{CO}_{2}$ concentration on the carbonate/bicarbonate equilibrium in the pore solution $[5,30,32,33]$, and it appears that such an exposure is not suitable for a well-defined pre-damaging of AAMs for subsequent steel corrosion studies.

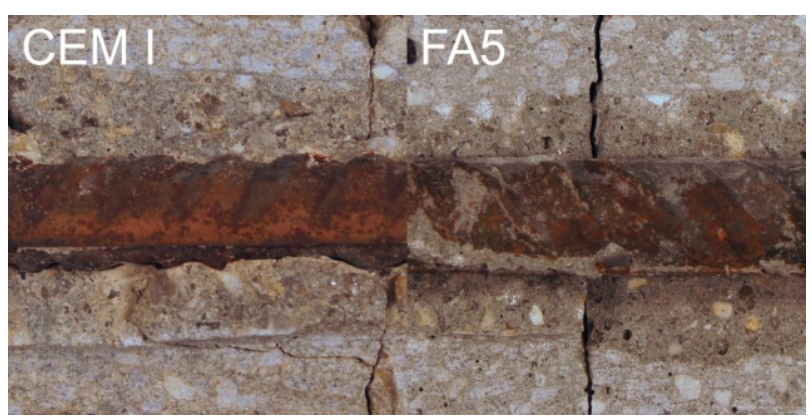

Fig. 7. Steel rebars embedded in CEM I-mortar (left) and FA5mortar (right) after $137 \mathrm{~d}$ under accelerated carbonation conditions (100\% $\mathrm{CO}_{2} ; 5$-mm mortar cover).

Exposure of the mortar specimens after $53 \mathrm{~d}$ to $\mathrm{NaCl}$ solution caused an additional decrease of $R_{\mathrm{p}}$, and a decrease of $E_{\text {corr }}$ too (Figs. 5 and 6). Likewise, $R_{\mathrm{el}}$ of both mortars decreased significantly, evolving to very low values for FA5 (Fig. 6). The observed decrease of $R_{\mathrm{el}}$ can be attributed to the uptake of water, and probably also to an increased ionic strength and thus increased conductivity of the pore solution.

\section{Conclusions and outlook}

The transport coefficients (diffusivity and permeability) of alkali-activated fly ash mortars have been found to differ by approx. one order of magnitude, depending on their mix-design (chemical composition of the fly ash, composition of the activator solution, addition of BFS), when tested without prior oven-drying. The lowest transport coefficients and carbonation depth were exhibited by the mortar with BFS addition, but the FA5-mortar (without BFS) too possessed chloride transport coefficients in the range of conventional cement-based materials $\left(\sim 20 \ldots 40 \times 10^{-12} \mathrm{~m}^{2} / \mathrm{s}\right)$. The two applied methods for the determination of chloride transport coefficients, rapid chloride migration ('RCM test') and accelerated diffusion, yielded comparable results.

Oven-drying of the BFS-containing mortar induced severe damage of its microstructure, rendering subsequent gas permeability measurements invalid.

Leaching in de-ionized water for $\sim 270 \mathrm{~d}$ did not induce a drop of $E_{\text {corr }}$ or $R_{\mathrm{p}}$ of embedded carbon steel rebars (5-mm mortar cover) in an alkali-activated fly ash mortar. That means that depassivation was not observed, demonstrating that the amount of sodium in the mortar, together with its $\mathrm{Na}^{+}$diffusion coefficient (estimated to 
be $\sim 0.5 \times 10^{-12} \mathrm{~m}^{2} / \mathrm{s}$ ), provided significant protection. The observed difference between $\mathrm{Na}^{+}$and $\mathrm{Cl}^{-}$diffusion coefficients warrants further studies on the underlying mechanisms.

Accelerated carbonation in a $100-\% \mathrm{CO}_{2}$ atmosphere led to depassivation of the steel in the alkali-activated fly ash mortars as well as in the CEM I-mortars within two weeks. In addition, $R_{\mathrm{el}}$ of the alkali-activated mortar decreased significantly during that period, suggesting microstructural alterations that may have caused coarsening of its pore structure. Thus, it can be concluded that accelerated carbonation in $100 \% \mathrm{CO}_{2}$ does not reproduce real-world conditions and may not be suited to induce well-defined pre-damaging of AAMs.

Future work will use the presented data to design test procedures for the determination of relevant chloride threshold values (critical chloride contents) of fly ashbased AAMs. The transport coefficients will be the basis to adjust the times needed to pre-damage specimens by leaching and/or carbonation before chloride penetration to simulate real-world conditions. The work will be augmented by microstructural analyses and the determination of pore solution compositions to gain insight into the mechanisms that control the ability of low-Ca AAMs to protect carbon steel reinforcement.

This work was supported by the German Federal Ministry for Economic Affairs and Energy via the Industrial Collective Research (IGF) programme of the AiF (IGF project $18910 \mathrm{~N}$ of the GfKORR e.V.). The authors acknowledge many valuable discussions on the durability of AAMs with the members of RILEM TC 247-DTA and EFC WP11/TG 'Steel Corrosion in Alkali-Activated Materials'.

\section{References}

1. S.A. Bernal, J.L. Provis, J. Am. Ceram. Soc. 97, 997-1008 (2014)

2. S. Mundra, S.A. Bernal, M. Criado, P. Hlaváček, G. Ebell, S. Reinemann, G.J.G. Gluth, J.L. Provis, RILEM Tech. Lett. 2, 33-39 (2017)

3. M. Holloway, J.M. Sykes, Corros. Sci. 47, 30973110 (2005)

4. M. Babbaee, A. Castel, Cem. Concr. Res. 88, 96107 (2016)

5. M. Babaee, M.S.H. Khan, A. Castel, Cem. Concr. Compos. 85, 32-43 (2018)

6. A. Buchwald, M Vanooteghem, E. Gruyaert, H. Hilbig, N. De Belie, Mater. Struct. 48, 501-511 (2015)

7. Q. Ma, S.V. Nanukuttan, P.A.M. Basheer, Y. Bai, C. Yang, Mater. Struct. 49, 3663-3677 (2016)

8. S. Mundra, M. Criado, S.A. Bernal, J.L. Provis, Cem. Concr. Res. 100, 385-397 (2017)

9. J.M. Miranda, A. Fernández-Jiménez, J.A. Gonzáles, A. Palomo, Cem. Concr. Res. 35, 1210-1217 (2005)

10. D.M. Bastidas, A. Fernández-Jiménez, A. Palomo, J.A. Gonzáles, Corros. Sci. 50, 1058-1065 (2008)
11. M. Criado, D.M. Bastidas, S. Fajardo, A. Fernández-Jiménez, J.M. Bastidas, Cem. Concr. Compos. 33, 644-652 (2011)

12. C. Monticelli, M.E. Natali, A. Balbo, C. Chiavari, F. Zanotto, S. Manzi, M.C. Bignozzi, Cem. Concr. Res. 80, 60-68 (2016)

13. C. Monticelli, M.E. Natali, A. Balbo, C. Chiavari, F. Zanotto, S. Manzi, M.C. Bignozzi, Cem. Concr. Res. 87, 53-63 (2016)

14. K. Kupwade-Patil, E.N. Allouche, J. Mater. Civ. Eng. 25, 1465-1476 (2013)

15. M.S. Badar, K. Kupwade-Patil, S.A. Bernal, J.L. Provis, E.N. Allouche, Constr. Build. Mater. 61, 7989 (2014)

16. W.D.A. Rickard, G.J.G. Gluth, K. Pistol, Cem. Concr. Res. 80, 33-43 (2016)

17. G.J.G. Gluth, W.D.A. Rickard, S. Werner, S. Pirskawetz, Mater. Struct. 49, 5243-5254 (2016)

18. A. Fernadez-Jimenez, I. García-Lodeiro, A. Palomo, J. Mater. Sci. 42, 3055-3065 (2007)

19. R.R. Lloyd, J.L. Provis, J.S.J. van Deventer, Cem. Concr. Res. 40, 1386-1392 (2010)

20. F. Škvára, V. Šmilauer, P. Hlaváček, L. Kopecký, Z. Cílová, Ceram.-Silik. 56, 374-382 (2012)

21. I. Ismael, S.A. Bernal, J.L. Provis, R. San Nicolas, D.G. Brice, A.R. Kilkullen, S. Hamdan, J.S.J van Deventer, Constr. Build. Mater. 48, 1187-1201 (2013)

22. C. Gunasekara, D.W. Law, S. Setunge, Constr. Build. Mater. 124, 352-362 (2016)

23. RILEM TC 116-PCD, Mater. Struct. 32, 174-179 (1999)

24. G. Ebell, A. Burkert, J. Fischer, J. Lehmann, T. Müller, D. Meinel, O. Paetsch, Mater. Corros. 67, 583-590 (2016)

25. P. Hlaváček, M. Rünger, G.J.G. Gluth, H.-C. Kühne, EuroCoalAsh 2017, Brno, Czech Republic, pp. 27-30 (2017)

26. M. Marks, M.A. Glinicki, K. Gibas, Materials 8, 8714-8727 (2015)

27. I. Ismail, S.A. Bernal, J.L. Provis, R. San Nicolas, S. Hamdan, J.S.J. van Deventer, Cem. Concr. Compos. 45, 125-135 (2014)

28. J.L. Provis, R.J. Myers, C.E. White, V. Rose, J.S.J. van Deventer, Cem. Concr. Res. 42, 855-864 (2012)

29. C. Gallé, Cem. Concr. Res. 31, 1467-1477 (2001)

30. S.A. Bernal, J.L. Provis, B. Walkley, R. San Nicolas, J.D. Gehman, D.G. Brice, A.R. Kilcullen, P. Duxson, J.S.J. van Deventer, Cem. Concr. Res. 53, 127-144 (2013)

31. A. Leemann, P. Nygaard, J. Kaufmann, R. Loser, Cem. Concr. Compos. 62, 33-43 (2015)

32. S.A. Bernal, J.L. Provis, D.G. Brice, A. Kilcullen, P. Duxson, J.S.J. van Deventer, Cem. Concr. Res. 42, 1317-1326 (2012) 
33. R. Pouhet, M. Cyr, Cem. Concr. Res. 88, 227-235 (2016) 